\title{
Sağlık Okuryazarlığının Diyet Kalitesine Etkisi
}

\author{
The Effect of Health Literacy on Diet Quality
}

\section{Müge Yılmaz ${ }^{1}$, Yağmur Yaşar Fırat² ${ }^{2}$ Fatma Hazan Gül ${ }^{3}$, Tutku Atuk Kahraman ${ }^{4}$}

Geliş tarihi/Received: 17.05.2021 • Kabul tarihi/Accepted: 08.07.2021

\section{ÖZET}

Amaç: Bu kesitsel araştırma, üniversite öğrencilerinin sağlık okuryazarlı̆̆ı düzeyinin diyet kalitesine etkisini belirlemek amaciyla yürütülmüştür.

Bireyler ve Yöntem: Çalı̧̧maya Erciyes Üniversitesi Sağlık Bilimleri Fakültesi Beslenme ve Diyetetik Bölümü (BD), Turizm Fakültesi (TF) ve Spor Bilimleri Fakültesindeki (SB) 580 gönüllü öğrenci dâhil edilmiştir. Sağlık okuryazarlığı "En Yeni Yaşamsal Bulgu Testiyle (NVS)”, diyet kalitesi “Sağlıklı Yeme İndeksi-2015 (SYİ-2105)”le saptanmıştır. Veriler yüz yüze görüşme yöntemiyle toplanmış, antropometrik ölçümler yapılmıştır. $\mathrm{p}<0.05$ değeri istatistiksel olarak anlamlı kabul edilmiştir.

Bulgular: Yeterli sağlık okuryazarlığı olanların oranı sırasıyla en yüksek BD (\%99.2), daha sonra SB (\%53.2), en az TF (\%31.2) öğrencilerinindir ( $p<0.001)$. Sağllk okuryazarlığı düzeyinin TF $(2.59 \pm 1.97)$ ve SB $(3.48 \pm 1.87)$ öğrencilerinin sinırlı, BD öğrencilerinin (5.55 \pm 0.68 ) yeterli olduğu saptanmıştır. Sağlık okuryazarlığı düzeyi yeterli olan öğrencilerin SYİ-2015 puanı

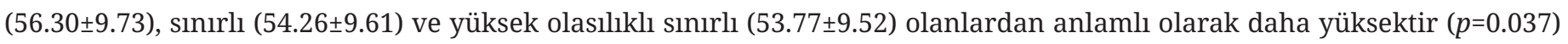
Sağlık okuryazarlığı düzeyi ile diyet kalitesi arasında pozitif yönlü zayıf anlamlı korelasyon saptanmıştır (rho=0.123, $p=0.003$ ). Bireylerin bel çevresi ve bel/kalça oranıyla NVS puanı, bel/kalça oranıyla SYİ-2015 puanı arasında negatif yönlü zaylf korelasyon bulunmuştur $(p<0.05)$.

Sonuç: Sağlık okuryazarlığı düzeyindeki artış diyetin kalitesini olumlu yönde etkilemekte, daha sağlıklı beslenme alışkanlığına sahip olunduğunu göstermektedir. BD öğrencilerinin sağlık okuryazarlığı düzeyinin ve diyet kalitelerinin SB ve TF öğrencilerine göre yüksek olması beklenen bir sonuçtur. Ancak BD öğrencileri için de SYİ-2015 puanı beklenenin altındadır ve diyetlerinin kalitelilerinin iyileştirilmesi gerekmektedir. Beslenmeyle yakından ilişkili olan TF ve SB fakültelerinin eğitim müfredatlarındaki beslenme ile ilgili derslerin sayısı ve saatlerinin artırılması önerilir.

Anahtar kelimeler: Diyet kalitesi, sağllk okuryazarlı̆̆l, Sağllklı Yeme İndeksi-2015, üniversite öğrencileri, Yeni Yaşamsal Bulgu Testi

\section{ABSTRACT}

Aim: This cross-sectional study was conducted to determine the effect of university students' health literacy level on diet quality.

1. İletişim/Correspondence: Erciyes Üniversitesi Sağlık Bilimleri Fakültesi Beslenme ve Diyetetik Bölümü, Kayseri, Türkiye

E-posta: muyilmaz@erciyes.edu.tr • 『 https://orcid.org/0000-0001-5998-1286

2. Erciyes Üniversitesi Sağlık Bilimleri Fakültesi Beslenme ve Diyetetik Bölümü, Kayseri, Türkiye • ๑ https://orcid.org/0000-0001-9028-5182
3. Erciyes Üniversitesi Sağllk Bilimleri Fakültesi Beslenme ve Diyetetik Bölümü, Kayseri, Türkiye • ๑ https://orcid.org/0000-0003-2776-808X

4. Erciyes Üniversitesi Sağllk Bilimleri Fakültesi Beslenme ve Diyetetik Bölümü, Kayseri, Türkiye - ๑ https://orcid.org/0000-0002-9327-3600 
Subjects and Method: A total of 580 volunteer students from Erciyes University Faculty of Health Sciences Department of Nutrition and Dietetics (ND), Tourism Faculty (TF), and Sport Sciences Faculty (SS) were included in the study. Health literacy was determined by the "Newest Vital Signs Test (NVS)" and diet quality by the "Healthy Eating Index-2015 (HEI-2105)". The data were collected by face-to-face interview method and anthropometric measurements were made. A value of $p<0.05$ was considered statistically significant.

Results: The proportion of those with sufficient health literacy is the highest in ND (99.2\%), then in SS (53.2\%), and the least in TF $(31.2 \%)$ students $(p<0.001)$. It was determined that the level of health literacy was limited for TF $(2.59 \pm 1.97)$ and SS (3.48 \pm 1.87$)$ students, while BD students' (5.55 \pm 0.68$)$ were sufficient. The HEI-2015 score of students with a sufficient level of health literacy (56.30 \pm 9.73$)$ is significantly higher than those with limited (54.26 \pm 9.61$)$ and high probability limited (53.77 \pm 9.52$)(p=0.037)$. A positive weak significant correlation was detected between health literacy level and diet quality ( $r h o=0.123, p=0.003)$. A negative weak correlation was found between the NVS score, the waist circumference, and the waist/hip ratio of the individuals and, the waist/hip ratio and the HEI-2015 score $(p<0.05)$.

Conclusion: The increase in the level of health literacy positively affects the quality of the diet, indicating a healthier eating habit. It is an expected result that the health literacy level and diet quality of ND students are higher than the SS and TF students. But still expected score is low for the ND students and their diet need improvement. It is recommended to increase the number and hours of courses on nutrition in the education curriculum of the TF and SS faculties closely related to nutrition.

Keywords: Diet quality, health literacy, Healthy Eating Index -2015, university students, The Newest Vital Sign

\section{GİRIŞ}

Bireylerin sağlıklı beslenmesi için ülkelere özgü hazırlanan beslenme rehberlerindeki besin gruplarından günlük önerilen porsiyonlarda tüketmesi gerekir. Böylece günlük gereksinimleri olan enerji ve besin ögesi ihtiyaçları da tam olarak karşılanmış olur. Sağlıklı beslenmede besin çeşitliliğinin sağlanması, bazı besin ve besin ögelerinin tüketiminin artırılması (taze sebze ve meyveler, balık, posa, D vitamini gibi) ya da azaltılması (tuz, şeker, doymuş yağ, trans yağ gibi) besin öğesi içeriği zengin besinlerin tercih edilmesi önemlidir (1). Diyet kalitesi terimi sağlıklı beslenme düzeyini yansıtmaktadır. Bireylerin diyet önerilerine ne kadar uyduklarını tanımlamak için kullanılan bir terimdir. Diyet kalite düzeyinin saptanması için Sağlıklı Yeme İndeksi (SYI), Akdeniz Diyet Skalası, Diyet Kalite İndeksi, Sağlıklı Diyet Göstergesi gibi indeksler geliştirilmiştir (2). Sağlıklı Yeme İndeksi Amerikan beslenme rehberlerindeki önerilere göre diyetin kalitesini ölçmek için yaygın olarak kullanılan bir indekstir. En güncel hali SYI-2015’tir (3).

Sağlık okuryazarlığı, bireylerin temel sağlık bilgilerini ve sağlıkla ilgili uygun kararları öğrenip, anlayıp, değerlendirmesi olarak tanımlanır. Sağlık okuryazarlığı düzeyi yetersiz olan bireyler koruyucu sağlık hizmetlerinden daha az yararlanmakta ve gereksiz hastane başvurularıyaparak sağlık hizmetleri harcamalarında artışa, erken teşhis edilebilen kronik hastalıklar için tarama sıklığında azalmaya böylece yüksek morbidite ve mortaliteye neden olmaktadır (4). Sağlık okuryazarlığı düzeyini ölçmek için çeşitli testler kullanılmaktadır. Bunlardan birisi de "En Yeni Yaşamsal Bulgu Testi (The Newest Vital Sign-NVS)"dir. Bir kutu dondurmanin besin etiketi üzerinde yazan bilgilerin anlaşılmasını ölçer (5).

Sağlık okuryazarlığı, tüketicilerin beslenmeyle ilgili bilgileri anlayabilmesi, eleştirel olarak değerlendirebilmesi ve bu bilgileri sağlıklı besin seçimi ve tüketimine yönelik doğru kararlar alarak uygulaması açısından önemlidir. Sağlık okuryazarlığı ile beslenme davranışı arasındaki ilişkiyi incelemek üzere Amerika'nın Maryland eyaletinde yürütülen bir çalışmada, sağlık okuryazarlığı düzeyi düşük olan bireylerin gelir düzeyinden bağımsız olarak sağlıksız beslendikleri gösterilmiştir. Sağlık okuryazarlığı 
düzeyi yeterli olan bireylerin ise kızartma türü besinleri nadiren tükettiği, taze meyveleri ise çoğunlukla kabuklu tercih ettiği belirlenmiştir (6). İngiltere'de yapılan başka bir çalışmada ise yüksek düzeyde sağlık okuryazarlığı ile yeterli miktarda sebze-meyve tüketimi arasında pozitif ilişki saptanmıştır (7). Amerika'nın Mississippi Eyaletinin kırsal bölgesinde yaşayan yetişkinlerin dâhil olduğu, sağlık okuryazarlığının diyet kalitesine etkisinin belirlendiği çalışmada; NVS testindeki her 1 puanlık artışın SYİ-2015 puanında 1.21 puanlık artışla ilişkili olduğu saptanmıştır. Ayrıca sağlık okuryazarlığındaki her 1 puanın, şekerle tatlandırılmış içeceklerden

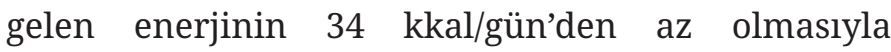
ilişkilendirilmiştir (8).

Sağlık okuryazarlığı düzeyi yüksek olan bireylerin diyetlerinin daha sağlıklı olduğu yapılan çalışmalarda kanıtlanmıştır (6-8). Literatür taramasında ülkemizde bu konuda yapılmış çalışmaya ulaşılamamıştır. Bu nedenle bu çalışma üniversite öğrencilerinin sağlık okuryazarlığının diyet kalitesine etkisini belirlemek amacıyla yapılmıştır.

\section{BİREYLER VE YÖNTEM}

\section{Araştırma Türü, Yeri, Zamanı ve Örneklem Özellikleri}

Bu kesitsel araştırmanın evrenini, 2019-2020 eğitim öğretim yılında Erciyes Üniversitesi Sağlık Bilimleri Fakültesi Beslenme ve Diyetetik Bölümü (BD, N=450), Turizm Fakültesi (TF, N=508) ve Spor Bilimleri Fakültesinde (SB, N=992) öğrenim gören toplam 1950 öğrenci oluşturmuştur. Evrenin tamamına ulaşılmaya çalışılmış, ancak araştırmaya katılmaya gönüllü 580 öğrenciyle (evrenin $\sim \% 30, B D n=250$, TF $n=80, S B$ $\mathrm{n}=250$ ) araştırma tamamlanmıştır. Araştırmaya 1824 yaş arası, kronik hastalığı olmayan bireyler dâhil edilmiştir.

Araştırmanın yürütülebilmesi için Erciyes Üniversitesi Sosyal ve Beşeri Bilimler Etik Kurul'dan onay alınmıştır (Karar No: 118 Karar Tarihi, 26.11 2019). Katılımcılara çalışmanın amacı açıklanmış ve “Gönüllü Onam Formu” aracılığıyla onayları alınmıştır.

\section{Verilerin Toplanması}

Veriler, öğrencilerin sosyo-demografik özelliklerini ve beslenme alışkanlıklarını (10 soru), NVS testini (6 soru), antropometrik ölçümlerini (vücut ağırlığı, boy uzunluğu, bel ve kalça çevresi) ve yapılandırılmış besin tüketim sıklığını (42 besin ve besin grubu) içeren anket formu aracılığıyla yüz yüze görüşme yöntemiyle toplanmıştır. Aile gelir durumu öğrencilerin kendi ifadelerine göre değerlendirilmiştir.

\section{Sağlık Okuryazarlığı Düzeyinin Saptanması}

Öğrencilerin sağlık okuryazarlığı düzeyi İngilizce “The Newest Vital Sign” (NVS) olan Türkçe’ye "En Yeni Yaşamsal Bulgu Testi” olarak çevrilmiş ölçek ile saptanmıştır. İlk kez 2005 yılında Weiss et al. (5) tarafından geliştirilen NVS, altı sorudan oluşmakta ve bireyin örnek bir besin etiketini okumasinı ve anlamasını ölçemektedir. Özdemir ve arkadaşları (9) tarafından 2010 yılında Türkçe'ye uyarlanan NVS testi, bir kutu dondurmanın besin etiketi üzerinde yazan bilgilere dair sorulardan oluşur ve testteki temel okuma-aritmetik becerisi gerektiren her bir sorunun doğru cevabi 1 puan değerindedir. NVS testinden 4-6 puan arası alanlar yeterli, 2-3 puan arası alanlar sınırlı ve 0-1 puan alanlar ise yüksek olasılıklı sınırlı sağlık okuryazarlığına sahip bireyler olarak değerlendirilmektedir (5).

\section{Diyet Kalitesinin Saptanması}

Öğrencilerin diyet kalitesi Sağlıklı Yeme İndeksi (SYI)2015 ile saptanmıştır. Sağlıklı Yeme İndeksi, Amerikalı bireylerin beslenme rehberlerindeki beslenme önerilerine ne kadar uyduklarını ve diyetin kalitesinin nasıl olduğunu ölçmek için kullanılmaktadır. Amerikan beslenme rehberi güncellendikçe, sYİde güncellenmektedir. En güncel hali SYI-2015'tir ve 13 diyet bileşeninden oluşmaktadır (3). Bu 13 bileşenin 9’u sağlıklı bir diyette bulunması önerilen besinleri, 4'ü ise sinırlı tüketilmesi gereken besinleri içermektedir. Toplam meyve, tam meyve, koyu yeşil yapraklı 
sebzeler/kurubaklagiller, toplam sebze, tam tahıllar, süt ve süt ürünleri, deniz ürünleri/bitkisel proteinler, toplam protein kaynakları, yağ asitleri diyette yeterli miktarda bulunması gereken bileşenlerdir. Rafine tahıllar, eklenmiş şeker, sodyum ve doymuş yağlar sinırlı tüketilmesi önerilen bileşenlerdir. İndeks puanları SYI-2015 hesap tablosunda belirtilen 1000 kkal başına düşen miktarlar ve günlük alınan enerjinin oransal olarak ne kadarına karşılık geldiğine göre değerlendirilmiştir. Bileşenlerin tüketimi miktarlarındaki artma veya azalma ile SYI puanı oransal olarak azaltılarak hesaplanmıştır. Toplam puan 0-100 arasındadır. Puan $>80$ ise diyet "kaliteli”, 51-80 arasında ise "geliştirilmeli" ve $<51$ ise "yetersiz” olarak tanımlanmıştır (3). İndeks puanının hesaplanması için yapılandırılmış besin tüketim sıklığı anketi kullanılmıştır.

\section{Besin Tüketiminin Saptanması/Besin Tüketim Sıklığı Anketi}

"Günde..../kez ve hiç tüketmiyorum" arasında 8 kategoriden oluşan 42 farklı besin ve besin grubunu içeren besin tüketim sıklığı kaydedilirken, besinlerin tüketim miktarları da sorgulanmış ve günlük tüketim miktarları hesaplanmıştır. Örneğin; haftada 3 kez 50 g kurubaklagil tüketen bir bireyin, haftalık toplam tükettiği kurubaklagil miktarı belirlenmiş (150 g), daha sonra bu değer 7’ye bölünerek günlük tüketim miktarı (21.4 g/gün) hesaplanmıştır. Tüketilen besinlerin porsiyon miktarları belirlenirken "Yemek ve Besin Fotoğraf Kataloğu” kullanılmıştır (10). Bireylerin günlük tükettikleri besinler 'Bilgisayar Destekli, Beslenme Bilgi Sistemleri (BeBis 2011-versiyon 7) programı kullanılarak bilgisayar ortamına girilmiş ve bireylerin günlük tükettikleri enerji ve besin ögeleri miktarları hesaplanmıştır (11).

\section{Antropometrik Ölçümler}

Bireylerin vücut ağırlığı, boy uzunluğu, bel ve kalça çevresi; ölçüm yöntemlerine uygun olarak yapılmıştır. Vücut ağırlığı elle taşınabilen 0.1 kg’a duyarlı, dijital baskül (Beurer GS 170, Germany) ile boy uzunluğu ise duvara dayalı şekilde esnemeyen bir mezur ile ölçülmüştür. Beden kütle indeksleri (BKİ) "vücut ağırlığı (kg)/boy uzunluğu (m)2" formülüyle hesaplanmıştır. Bireylerin en alt kaburga kemiğiyle kristailiyak arasının orta noktasından geçen bölgeden bel çevreleri, kalçanın en yüksek noktasından kalça çevreleri esnemeyen mezurayla ölçülmüştür. Bel/ kalça ve bel/boy oranları hesaplanmıştır (12).

\section{Verilerin İstatistiksel Değerlendirmesi}

Verilerin istatistiksel analizi IBM Statistical Package for the Social Sciences (SPSS) programı 25.0 versiyonuyla yapılmıştır. Tanımlayıcı istatistikler birim sayısı $(n)$, yüzde (\%), ortalama \pm standart sapma $(\overline{\mathrm{X}} \pm$ SD) olarak verilmiştir. Verilerin dağılımı Shapiro Wilk normallik testi ile değerlendirilmiştir. Üç bağımsız grubun karşılaştırmaları Tek Yönlü Varyans Analizi (ANOVA) ile değerlendirilmiş ve post hoc çoklu karşılaştırmada Tukey testi kullanılmıştır. Kategorik değişkenler arası ilişki Fisher Exact test ve Pearson Exact Ki-kare test ile incelenmiştir. NVS, SYİ-2015 puanları, antropometrik ölçümler arasındaki ilişki Pearson korelasyon analizi ile incelenmiştir. $p<0.05$ değeri istatistiksel olarak anlamlı kabul edilmiştir.

\section{BULGULAR}

Sağlık okuryazarlığı düzeyinin diyet kalitesini etkisini saptamak amacıyla yapılan bu kesitsel çalışmaya, TF $(n=80), S B(n=250)$ ve BD $(n=250)$ öğrenim gören 580 gönüllü öğrenci dâhil olmuştur.

Çalışma grubunun yaş ortalaması $21.22 \pm 1.91$ yıl ve BKI ortalaması $22.07 \pm 2.93 \mathrm{~kg} / \mathrm{m}^{2}$ olup BD öğrencilerinin yaşı diğer iki bölümdeki öğrencilerden anlamlı olarak daha yüksek iken, BKİ değeri anlamlı olarak daha düşük bulunmuştur $(p<0.05)$. BD kadın öğrencilerin oranı (\%92.0) TF ve SB'den (\%43.8, \%38.8, sirasıyla) anlamlı olarak daha yüksektir $(p<0.001)$. Birinci sınıf öğrencilerin oranı TF (\%40), 2. sınıf öğrencilerin oranı SB (\%33.2), 3. sinıf öğrencilerin oranı BD’de (\%36.3) anlamlı olarak daha yüksektir $(p<0.001)$. SB öğrencilerinden ailesiyle birlikte yaşayanların oranı (\%66.4), BD ve TF öğrencilerinde yurtta kalanların oranı (sirasıyla \%52.0, \%36.2) önemli düzeyde daha yüksektir $(p<0.001)$. BD öğrencilerinde sigara 
Tablo 1. Öğrencilerin bölümlerine göre bazı özelliklerinin dağılımı

\begin{tabular}{|c|c|c|c|c|c|c|c|}
\hline \multirow[t]{2}{*}{ Özellikler } & \multicolumn{2}{|c|}{$\begin{array}{c}\text { Turizm Fakültesi } \\
(\mathbf{n}=\mathbf{8 0})\end{array}$} & \multicolumn{2}{|c|}{$\begin{array}{l}\text { Spor Bilimleri Fakültesi } \\
(\mathrm{n}=250)\end{array}$} & \multicolumn{2}{|c|}{$\begin{array}{l}\text { Beslenme ve Diyetetik Bölümü } \\
(n=250)\end{array}$} & \multirow[t]{2}{*}{$p$} \\
\hline & $\mathbf{n}$ & $\%$ & $\mathbf{n}$ & $\%$ & $\mathbf{n}$ & $\%$ & \\
\hline \multicolumn{8}{|l|}{ Cinsiyet } \\
\hline Erkek & $45^{\mathrm{a}}$ & 56.3 & $153^{\mathrm{a}}$ & 61.2 & $20^{\mathrm{b}}$ & 8.0 & \multirow{2}{*}{$<0.001$} \\
\hline Kadın & $35^{\mathrm{a}}$ & 43.7 & $97^{a}$ & 38.8 & $230^{\mathrm{b}}$ & 92.0 & \\
\hline \multicolumn{8}{|l|}{ Sinifi } \\
\hline 1 & $32^{\mathrm{a}}$ & 40.0 & $52^{\mathrm{b}}$ & 20.8 & $66^{\mathrm{a}, \mathrm{b}}$ & 26.4 & \multirow{4}{*}{$<0.001$} \\
\hline 2 & $13^{\mathrm{a}}$ & 16.3 & $83^{b}$ & 33.2 & $42^{\mathrm{a}}$ & 16.8 & \\
\hline 3 & $16^{\mathrm{a}}$ & 20.0 & $57^{\mathrm{a}}$ & 22.8 & $92^{\mathrm{b}}$ & 36.8 & \\
\hline 4 & $19^{\mathrm{a}}$ & 23.7 & $58^{\mathrm{a}}$ & 23.2 & $50^{\mathrm{a}}$ & 20.0 & \\
\hline \multicolumn{8}{|l|}{ Yaşadığı yer/bireyler } \\
\hline Ailesiyle birlikte & $41^{\mathrm{a}}$ & 51.3 & $166^{\mathrm{b}}$ & 66.4 & $97^{\mathrm{a}}$ & 38.8 & \multirow{3}{*}{$<0.001$} \\
\hline Arkadaşıyla birlikte & $10^{\mathrm{a}, \mathrm{b}}$ & 12.5 & $41^{\mathrm{b}}$ & 16.4 & $23^{a}$ & 9.2 & \\
\hline Yurt & $29^{\mathrm{a}}$ & 36.2 & $43^{b}$ & 17.2 & $130^{\mathrm{a}}$ & 52.0 & \\
\hline \multicolumn{8}{|l|}{ Aile gelir durumu } \\
\hline Gelir giderden az & $36^{\mathrm{a}}$ & 45.0 & $82^{\mathrm{a}}$ & 32.8 & $41^{\mathrm{b}}$ & 16.4 & \multirow{3}{*}{$<0.001$} \\
\hline Gelir gidere eşit & $28^{\mathrm{a}}$ & 35.0 & $129^{\mathrm{b}}$ & 51.6 & $177^{c}$ & 70.8 & \\
\hline Gelir giderden fazla & $16^{\mathrm{a}}$ & 20.0 & $39^{\mathrm{a}}$ & 15.6 & $32^{\mathrm{a}}$ & 12.8 & \\
\hline \multicolumn{8}{|l|}{ Sigara içme } \\
\hline İçiyor & $28^{\mathrm{a}}$ & 35.0 & $88^{\mathrm{a}}$ & 35.2 & $24^{\mathrm{b}}$ & 9.6 & \multirow{2}{*}{$<0.001$} \\
\hline İçmiyor & $52^{\mathrm{a}}$ & 65.0 & $162^{\mathrm{a}}$ & 64.8 & $226^{b}$ & 90.4 & \\
\hline \multicolumn{8}{|l|}{ Öğün sayısı } \\
\hline <3 öğün & $33^{\mathrm{a}}$ & 41.2 & $78^{\mathrm{a}}$ & 31.2 & $15^{\mathrm{b}}$ & 6.0 & \multirow{3}{*}{$<0.001$} \\
\hline 3-6 öğün & $46^{\mathrm{a}}$ & 57.5 & $165^{\mathrm{a}}$ & 66.0 & $229^{b}$ & 91.6 & \\
\hline >6 öğün & $1^{\mathrm{a}}$ & 1.3 & $7^{\mathrm{a}}$ & 2.8 & $6^{\mathrm{a}}$ & 2.4 & \\
\hline \multicolumn{8}{|l|}{ öğün atlama } \\
\hline Atlarım & $63^{\mathrm{a}, \mathrm{b}}$ & 78.8 & $183^{b}$ & 73.2 & $222^{\mathrm{a}}$ & 88.8 & \multirow{2}{*}{$<0.001$} \\
\hline Atlamam & $17^{\mathrm{a}, \mathrm{b}}$ & 21.2 & $67^{\mathrm{b}}$ & 26.8 & $28^{\mathrm{a}}$ & 11.2 & \\
\hline \multicolumn{8}{|c|}{ Kahvaltı öğünü atlama } \\
\hline Atlarım & $25^{\mathrm{a}}$ & 31.2 & $73^{\mathrm{a}}$ & 29.2 & $38^{\mathrm{b}}$ & 15.2 & \multirow{2}{*}{$<0.001$} \\
\hline Atlamam & $55^{\mathrm{a}}$ & 68.8 & $177^{\mathrm{a}}$ & 70.8 & $212^{\mathrm{b}}$ & 84.8 & \\
\hline \multicolumn{8}{|c|}{ Vitamin-mineral takviyesi kullanım durumu } \\
\hline Evet & $4^{\mathrm{a}}$ & 5.0 & $14^{\mathrm{a}}$ & 5.6 & $62^{\mathrm{b}}$ & 24.8 & \multirow[t]{2}{*}{$<0.001$} \\
\hline Hayır & $76^{\mathrm{a}}$ & 95.0 & $236^{\mathrm{a}}$ & 94.4 & $188^{b}$ & 75.2 & \\
\hline Yaş $(\overline{\mathrm{X}} \pm \mathrm{SD})$ & \multicolumn{2}{|c|}{$20.7 \pm 1.96^{\mathrm{a}}$} & \multicolumn{2}{|c|}{$20.96 \pm 1.82^{\mathrm{a}}$} & \multicolumn{2}{|c|}{$21.65 \pm 1.90^{\mathrm{b}}$} & $<0.001$ \\
\hline BKİ $(\overline{\mathbf{X}} \pm \mathrm{SD})$ & \multicolumn{2}{|c|}{$22.67 \pm 3.93^{\mathrm{a}}$} & & & & & 0.006 \\
\hline
\end{tabular}

$\overline{a, b}$ arasında anlamlı farklllık vardır. Verilerin analizinde Pearson ki-kare testi kullanılmıştır.

içmeyenlerin oranı (\%90.4) diğer iki gruptan anlamlı olarak daha yüksektir $(p<0.001)$. BD öğrencilerde 3-6 öğün tüketenlerin oranı (\%91.6) diğer iki bölümden, TF ve SB öğrencilerinde 3 öğünden az tüketenlerin oranı (sirasıyla \%41.2, \%31.2) BD’den önemli düzeyde yüksektir $(p<0.001)$. BD öğrencilerinde öğün atlayanların oranı (\%88.8) diğer iki bölümden anlamlı olarak yüksek bulunurken, kahvaltı öğününü atlama oranı (\%15.2) diğer bölümlerdeki öğrencilerden anlamlı olarak düşük bulunmuştur $(p<0.001)$. BD öğrencilerinde besin desteği kullananların oranı (\%24.8) daha yüksektir ( $p<0.001$, Tablo 1$)$. 
Tablo 2. Öğrencilerin bölümlerine göre sağlık okuryazarlık düzeylerinin ve diyet kalitelerinin karşılaştırılması

\begin{tabular}{|c|c|c|c|c|c|c|c|c|c|c|}
\hline & \multirow[t]{2}{*}{ Puan } & \multicolumn{2}{|c|}{$\begin{array}{c}\text { Turizm } \\
\text { Fakültesi } \\
(\mathbf{n}=\mathbf{8 0})\end{array}$} & \multicolumn{2}{|c|}{$\begin{array}{l}\text { Spor Bilimleri } \\
\text { Fakültesi } \\
(n=250)\end{array}$} & \multicolumn{2}{|c|}{$\begin{array}{c}\text { Beslenme ve Diyetetik } \\
\text { Bölümü } \\
(\mathbf{n}=250)\end{array}$} & \multicolumn{2}{|c|}{$\begin{array}{l}\text { Toplam } \\
(n=580)\end{array}$} & \multirow[t]{2}{*}{$p$} \\
\hline & & $\mathbf{n}$ & $\%$ & $\mathbf{n}$ & $\%$ & $\mathbf{n}$ & $\%$ & $\mathbf{n}$ & $\%$ & \\
\hline \multicolumn{11}{|l|}{ Sağlık okuryazarlığı* } \\
\hline Yüksek olasılıklı sınırlı & $0-1$ & $28^{\mathrm{a}}$ & 35.0 & $45^{b}$ & 18.0 & $0^{c}$ & 0.0 & 73 & 12.6 & \\
\hline Sinirlı & $2-3$ & $27^{\mathrm{a}}$ & 33.8 & $72^{\mathrm{a}}$ & 28.8 & $2^{\mathrm{b}}$ & 0.8 & 101 & 17.4 & $<0.001$ \\
\hline Yeterli & $4-6$ & $25^{\mathrm{a}}$ & 31.2 & $133^{b}$ & 53.2 & $248^{c}$ & 99.2 & 406 & 70.0 & \\
\hline \multicolumn{11}{|l|}{ Diyet kalitesi* } \\
\hline Yetersiz & $<51$ & $44^{\mathrm{a}}$ & 55.0 & $91^{b}$ & 36.4 & $70^{\mathrm{b}}$ & 28.0 & 205 & 35.3 & \\
\hline Geliştirilmeli & $51-80$ & $36^{\mathrm{a}}$ & 45.0 & $157^{\mathrm{b}}$ & 62.8 & $178^{\mathrm{b}}$ & 71.2 & 371 & 64.0 & $<0.001$ \\
\hline Kaliteli & $>80$ & $0^{\mathrm{a}}$ & 0 & $2^{\mathrm{a}}$ & 0.8 & $2^{\mathrm{a}}$ & 0.8 & 4 & 0.7 & \\
\hline NVS testi puanı $(\overline{\mathrm{X}} \pm \mathrm{SD})$ & & \multicolumn{2}{|c|}{$2.59 \pm 1.97^{\mathrm{a}}$} & \multicolumn{2}{|c|}{$3.48 \pm 1.87^{\mathrm{b}}$} & \multicolumn{2}{|c|}{$5.55 \pm 0.68^{b}$} & \multicolumn{2}{|c|}{$4.25 \pm 1.90$} & $<0.001$ \\
\hline SYİ-2015 puanı $(\overline{\mathrm{X}} \pm S D)$ & & \multicolumn{2}{|c|}{$51.12 \pm 8.14^{a}$} & \multicolumn{2}{|c|}{$55.42 \pm 10.16^{b}$} & \multicolumn{2}{|c|}{$57.26 \pm 9.32^{\mathrm{c}}$} & \multicolumn{2}{|c|}{$55.62 \pm 9.73$} & $<0.001$ \\
\hline
\end{tabular}

Tablo 2'ye bakıldığında NVS göre yeterli sağlık okuryazarlığı olanların oranı sırasıyla en yüksek BD (\%99.2), daha sonra SB (\%53.2), en az TF (\%31.2) öğrencilerinde olduğu görülmekte olup her üç bölümün oranları arasındaki fark istatistiksel olarak anlamlıdır $(p<0.001)$. TF öğrencilerinin NVS puan ortalamaları $(2.59 \pm 1.97)$, SB $(3.48 \pm 1.87)$ ve BD öğrencilerinin puan ortalamalarından $(5.55 \pm 0.68)$ anlamlı olarak daha düşük bulunmuştur $(p<0.001)$. Üç grup ikişerli sYİ-2015 puan ortalamalarına göre karşılaştırıldığında diyet kaliteleri arasında istatistiksel olarak anlamlı fark olduğu saptanmıştır $(p<0.001)$. SYİ-2015 puan ortalaması en yüksek olan bölüm öğrencileri BD (57.26 \pm 9.32$)$, sonra SB

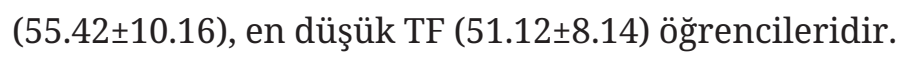
Katılımcıların SYİ-2015 puanları sınıflandırıldığında tüm öğrenciler arasında yeterli diyet kalitesine sahip olanların oranı $(\% 0.7)$ çok düşüktür. Geliştirilmesi gereken diyet kalitesine sahip olan öğrenci oranı BD (\%71.2) ve SB (\%62.8)'nin TF (\%45.0)'den; yetersiz diyet kalitesine sahip olanların oranı TF (\%55)'nin SB (\%36.4) ve BD (\%28)'den anlamlı olarak daha yüksek bulunmuştur ( $p<0.001$, Tablo 2$)$.

Sağlık okuryazarlığı düzeyi yeterli olanların SYİ2015 toplam puan $(56.30 \pm 9.73)$, tam meyve, toplam sebze, tam tahıl, süt ve süt ürünleri ve deniz ürünleri/ bitkisel proteinler alt bileşen puan ortalamaları sinırlı ve yüksek olasılıklı sinırlı olanlardan anlamlı olarak daha yüksek; yağ asitleri ve doymuş yağ alt bileşen puan ortalamaları anlamlı olarak daha düşük bulunmuştur ( $p<0.05$, Tablo 3$)$.

Sağlık okuryazarlığı düzeyi yeterli olanların \%70.9’u kadınken yüksek olasılıklı sınırlıların \%65.8'i erkektir $\left(\mathrm{x}^{2}=45.5, p<0.001\right)$. Sağlık okuryazarlığı düzeyi sinırlı olanlarda kadın (\%48.5) ve erkek (\%51.5) oranı farklı değildir. Sağlık okuryazarlığı düzeyi yeterli olanlarda geliri giderine eşit $(\% 62.6)$ ve geliri giderinden fazla (\%14.5) olanların oranı, yüksek olasılıklı sınırlılardan (sırasıyla \%43.8, \%13.7) anlamlı olarak yüksektir $\left(\mathrm{x}^{2}=17.5, p=0.001\right)$ (Tabloda verilmeyen bulgular).

Çalışma grubunun tamamında ve BD öğrencilerinin sağlık okuryazarlığı düzeyiyle diyet kalitesi arasında pozitif yönlü zayıf anlamlı korelasyon saptanmıştır $(p<0.05$, Tablo 4).

Bireylerin bel çevresi ve bel/kalça oranıyla NVS puanı arasında, bel/kalça oranıyla SYİ-2015 puanı arasında negatif yönlü zayıf korelasyon bulunmuştur $(p<0.05$, Tablo 5). 
Tablo 3. Öğrencilerin sağlık okuryazarlığı sınıflamasına göre SYİ-2015 bileşen puan ortalamalarının karşılaştırılması

\begin{tabular}{|c|c|c|c|c|}
\hline $\begin{array}{l}\text { SYI-2015 Bileşenleri } \\
\text { (en yüksek puan) }\end{array}$ & $\begin{array}{c}\text { Yüksek Olasılıklı } \\
\text { Sinırlı } \\
(\mathrm{n}=73) \\
\overline{\mathrm{X}} \pm S D\end{array}$ & $\begin{array}{c}\text { Sinirlı } \\
(\mathrm{n}=101) \\
\overline{\mathrm{X}} \pm S D\end{array}$ & $\begin{array}{c}\text { Yeterli } \\
(\mathrm{n}=406) \\
\overline{\mathrm{X}} \pm S D\end{array}$ & $p$ \\
\hline Toplam meyve (5) & $2.75 \pm 1.92$ & $2.85 \pm 1.96$ & $2.87 \pm 1.70$ & 0.868 \\
\hline Tam meyve (5) & $2.75 \pm 1.92^{\mathrm{a}}$ & $2.85 \pm 1.96^{\mathrm{a}}$ & $3.43 \pm 1.83^{\mathrm{b}}$ & 0.001 \\
\hline Toplam sebze (5) & $0.52 \pm 0.88^{\mathrm{a}}$ & $0.70 \pm 1.05^{\mathrm{a}}$ & $2.17 \pm 1.79^{b}$ & $<0.001$ \\
\hline Yeşil sebzeler ve kuru baklagiller (5) & $1.56 \pm 1.62$ & $1.71 \pm 1.88$ & $1.82 \pm 1.78$ & 0.476 \\
\hline Tam tahillar (10) & $6.62 \pm 3.51^{\mathrm{a}}$ & $6.98 \pm 3.23^{\mathrm{a}}$ & $8.10 \pm 2.75^{b}$ & $<0.001$ \\
\hline Süt ve süt ürünleri (10) & $1.66 \pm 1.41^{\mathrm{a}}$ & $1.91 \pm 1.84^{\mathrm{a}}$ & $3.36 \pm 2.33^{b}$ & $<0.001$ \\
\hline Toplam proteinli besinler (5) & $3.96 \pm 1.15$ & $3.84 \pm 1.48$ & $3.83 \pm 1.37$ & 0.760 \\
\hline Deniz ürünleri ve bitkisel proteinler (5) & $0.05 \pm 0.22^{\mathrm{a}}$ & $0.13 \pm 0.50^{\mathrm{a}}$ & $1.99 \pm 1.78^{b}$ & $<0.001$ \\
\hline Yağ asitleri (10) & $4.07 \pm 2.81^{\mathrm{a}}$ & $3.45 \pm 2.92^{\mathrm{a}}$ & $2.56 \pm 2.71^{\mathrm{b}}$ & $<0.001$ \\
\hline Rafine tahillar (10) & $4.29 \pm 3.67$ & $4.48 \pm 3.77$ & $4.77 \pm 3.79$ & 0.528 \\
\hline Sodyum (10) & $9.96 \pm 0.26$ & $9.95 \pm 0.26$ & $9.93 \pm 0.45$ & 0.739 \\
\hline Doymuş yağlar (10) & $9.64 \pm 0.98^{\mathrm{a}}$ & $9.36 \pm 1.65^{\mathrm{a}}$ & $4.95 \pm 4.31^{\mathrm{b}}$ & $<0.001$ \\
\hline İlave şeker (10) & $5.70 \pm 3.43$ & $6.00 \pm 3.19$ & $6.52 \pm 3.41$ & 0.090 \\
\hline Toplam puan & $53.77 \pm 9.52$ & $54.26 \pm 9.61$ & $56.30 \pm 9.73$ & 0.037 \\
\hline
\end{tabular}

a,b arasinda anlaml farklllk vardır.

Verilerin analizinde tek yönlü varyans analizi ve Post-hoc analizlerde Tukey testi kullanılmıştır.

SYİ: Sağllklı Yeme İndeksi

Tablo 4. Öğrencilerin bölümlerine göre NVS ve SYİ-2015 puanları arasındaki ilişki

\begin{tabular}{lcc}
\hline & $\boldsymbol{r}$ & $\boldsymbol{p}$ \\
\hline Turizm Fakültesi (n=80) & -0.210 & 0.061 \\
Spor Bilimleri Fakültesi (n=250) & 0.035 & 0.581 \\
Beslenme ve Diyetetik Bölümü (n=250) & 0.158 & $\mathbf{0 . 0 1 3}$ \\
Toplam (n=580) & 0.123 & $\mathbf{0 . 0 0 3}$ \\
\hline
\end{tabular}

Verilerin analizinde Pearson korelasyon testi kullanılmıştır. NVS: En yeni Yaşamsal Bulgu Testi, SYİ: Sağllklı Yeme İndeksi

Tablo 5. Öğrencilerin NVS ve SYI-2015 puanları ile antropometrik ölçümleri arasındaki ilişki

\begin{tabular}{|c|c|c|c|c|}
\hline & \multicolumn{2}{|c|}{ NVS } & \multicolumn{2}{|c|}{ SYİ } \\
\hline & $\mathbf{R}$ & $\mathbf{P}$ & $\mathbf{r}$ & $\mathbf{P}$ \\
\hline BKİ $\left(\mathrm{kg} / \mathrm{m}^{2}\right)$ & -0.015 & 0.717 & 0.054 & 0.192 \\
\hline Bel çevresi (cm) & -0.105 & 0.011 & -0.045 & 0.278 \\
\hline Kalça çevresi (cm) & 0.004 & 0.925 & 0.103 & 0.013 \\
\hline Bel/kalça oranı & -0.132 & 0.001 & -0.112 & 0.007 \\
\hline Bel/boy oranı & -0.024 & 0.567 & 0.002 & 0.963 \\
\hline
\end{tabular}

Verilerin analizinde Pearson korelasyon testi kullanılmıştır. BKİ: Beden Kütle İndeksi, NVS: En yeni Yaşamsal Bulgu Testi, SYİ: Sağglklı Yeme İndeksi

\section{TARTIŞMA}

Sağlıklı beslenme bir başka değişle iyi kalitedeki bir diyet, sağlığın sürdürülmesi ve hastalıkların önlenmesinde büyük önem taşır. Sağlıklı beslenme önerileri hakkında yeterli bilgi birikimi olmasına rağmen, toplumun beslenme alışkanlıklarını iyileştirmeye yönelik programlar yeterince başarılı olamamaktadır. Toplum sağlığının gelişmesine katkı sağlayacak pratik stratejilerden biri besin etiketi okuma alışkanlığının kazandırılmasıdır (1). 
$\mathrm{Bu}$ çalışmada sağlık okuryazarlığı düzeyinin belirlenmesinde besin etiketi bilgilerine dair soruları içeren NVS testi kullanılmıştır. Sağlık okuryazarlığı düzeyindeki artışın diyetin kalitesini olumlu yönde etkilediği bulunmuştur.

Amerika Ulusal Beslenme ve Sağlık Araştırması 20052006 yılı sonuçlarında kadınların, eğitim ve ekonomik düzeyi yüksek bireylerin daha fazla besin etiketi okudukları bildirilmiştir (13). Birinci basamak sağlık kurumuna başvuran yetişkinler üzerinde yapılan bir çalışmada eğitim düzeyi ve gelir düzeyi arttıkça besin etiketindeki bilgilerin anlaşılmasının artığı saptanmıştır (14). Amacı sağlık okuryazarlığı ve diyet kalitesi ilişkisini değerlendirmek olan çalışmada da kadınların sağlık okuryazarlık puanı erkelerden daha yüksek bulunmuştur (8). Bu çalışmada da gelir düzeyi daha iyi olanların ve kadınların sağlık okuryazarlık düzeyinin daha yüksek olduğu saptanmıştır. Ancak BD öğrencilerinde kadınların oranın diğer bölümlerden daha yüksek olması bu durumu etkilemiş olabilir. Katılımcıların üniversite öğrencisi olması \%70’nin yeterli sağlık okuryazarlığı düzeyine sahip olmasını açıklayabilir (Tablo 2). Beslenme ve Diyetetik bölümü öğrencilerinin tamamına yakının besin etiketi üzerindeki bilgilere dair soruları yeterli düzeyde cevaplamalarının nedeni; eğitimlerinin yanı sıra 3. sınıfta okuyan öğrencilerin oranının yüksekliği olabilir (Tablo 1). Sağlık okuryazarlığının bu çalışmaya benzer şekilde NVS testiyle belirlendiği Kolombiyalı üniversite öğrencileri üzerinde yürütülen pilot çalışmada öğrencilerin \%83’ünün yeterli, \%17'sinin sınırlı sağlık okuryazarlığı düzeyine sahip oldukları bulunmuştur (15). Bir başka çalışmada, adölesan kız öğrencilerin NVS testine göre \%51.5'nin yetersiz, \%37'sinin sinırlı ve \%11.5'nin yeterli sağlık okuryazarlığı düzeyine sahip oldukları belirlenmiştir (16). Bu çalışmada sağlık okuryazarlığı düzeyi yeterli olanların oranı \%70, sinırlı olanların \%17.4 ve yüksek olasılıklı sınırlı olanların oranı \%12.6 olarak bulunmuştur (Tablo 2). Çalışma sonuçları eğitim düzeyinin artmasıyla sağlık okuryazarlığı düzeyinin de arttığını desteklemektedir.
Besin etiketi okumak daha sağlıklı besin seçimini desteklemenin bir yoludur (14). Yapılan çalışmalarda, besin etiketi okuyan bireylerin enerji, yağ, doymuş yağ, kolesterol, sodyum gibi besin öğelerini ve atıştırmalıklar, tatlılar gibi sağlıksız yiyeceklerin tüketimini sinırlandırarak; meyve, sebze, posa tüketimini artırarak sağlıklı beslenmeyi tercih ettikleri bildirilmiştir. Ayrıca öğün sayllarına ve öğün atlamamaya dikkat ettikleri saptanmıştır $(13,17)$. Sağlık okuryazarlığı düzeyinin artması ile diyet kalitesinin de arttığı bildirilmiştir (6-8). Sağlık okuryazarlığı ve diyet kalitesi arasındaki ilişkinin değerlendirildiği çalışmada NVS testindeki her 1 puanlık artışın SYI puanında 1.21 puanlık artış sağlayacağı saptanmıştır (8). Bu çalışmada, NVS test puanına göre sağlık okuryazarlığı düzeyi yeterli olan bireylerin SYI-2015 puan ortalamasının yani diyet kalitesi düzeyinin yüksek çıkması (Tablo 3) ayrıca sağlık okuryazarlığındaki artışın diyet kalitesini de artırdığının bulunması (Tablo 4) besin etiketini anlayanların daha sağlıklı beslendiğini göstermektedir. Yeterli sağlık okuryazarlığı olanların (besin etiketini daha doğru anlayanların) diyet kalitesinin alt bileşenlerden günlük sebze, meyve, tam tahıl tüketim miktarı daha yüksek; doymuş yağ tüketiminin daha düşük olduğu saptanması (Tablo 3) yukarıda bahsi geçen çalışma bulgularını desteklemektedir. Özellikle BD okuyan öğrencilerin sağlık okuryazarlığı düzeyinin en yüksek olması ve diyet kalitesi düzeyinin $\mathrm{BD}$ ve SB öğrencilerinde TF öğrencilerine göre daha yüksek bulunması (Tablo 2) sağlık bilincinin gelişmesini sağlayan beslenme ve spor eğitiminin etkisini ortaya koymaktadır. Genç yetişkinlerin dahil olduğu çalışmada, bu araştırma bulgularının aksine, sağlık okuryazarlığı ile diyet kalitesi arasında korelasyon saptanmamıştır (18). $\mathrm{Bu}$ araştırmada BD öğrencilerinin SYİne göre diyet kalitelerinin geliştirilmesi gereken puan aralığında (57.26 \pm 9.32$)$ olmasının nedenleri; öğrencilerin \%43.2'sinin birinciveikinci sınıfta olmalarından dolayı sağlıklı beslenme bilincinin yeterince gelişmemiş olması; \%52.0'sinin yurtta kalması ve \%72.0'sinin geliri giderin denk olmasından dolayı sağlıklı besine 
ulaşım zorluğu olarak açıklanabilir. Aynı çalışmada, sağlık okuryazarlığı ile eğitim düzeyi arasında pozitif yönlü korelasyon bulunurken BKİyle korelasyon bulunmamıştır (18). Adölesan kız öğrencilerle yapılan çalışmada ise BKİyle sağlık okuryazarlığı düzeyi arasında negatif yönlü korelasyon saptanmıştır (16). $\mathrm{Bu}$ çalışmada, sağlık okuryazarlığıyla BKİ arasında ilişki bulunmazken bel çevresi ve bel/kalça oranı arasında negatif yönlü korelasyon saptanmıştır (Tablo 5). Ortanca yaşı 11.5 (10.0-16.0) yıl olan çocukların dâhil olduğu çalışmada sağlık okuryazarlığı düzeyi ile yaş arasında pozitif yönlü ilişki saptanmış ve çocukların sağlık okuryazarlığı düzeyinin BKİnin güçlü bir öngörücüsü olduğu bildirilmiştir. Çocukların sağlık okuryazarlığındaki her 1 puanlık artışın BKİ z-skorunda 0.02 puan azalma sağladığı saptanmıştır. Çocukluk çağında yeterli sağlık okuryazarlığı düzeyine sahip olunması yani bireyin sağlığıyla ilgili doğru kararları vermesi için gerekli sağlık bilgilerini okuma ve yorumlama becerisinin gelişmesi yetişkinlik dönemindeki sağlığını etkilemektedir (19). Bu çalışmaların sonuçları genç yaşlarda sağlık okuryazarlığı düzeyindeki artışla daha sağlıklı besinlerin seçilmesinin bireylerin yetişkinlik döneminde de obezite riskinde azalma sağlayacağını düşündürmektedir. Düşük sağlık okuryazarlığı, sağlık sistemlerinin ve kaynaklarının verimsiz kullanımına neden olur. Sağlık okuryazarlığının iyileştirilmesi, genç yetişkinlerde diyet kalitesini arttırmak için önemlidir. Ayrıca toplumların sağlık okuryazarlığı düzeyinin artırılması obezite ile mücadelede etkili bir yoldur (20).

Ülkemizde üniversite öğrencileri arasında özellikle kahvaltı öğününü atlama önemli bir sorundur $(21,22)$. Bu çalışmada da TF ve SB öğrencilerinin yaklaşık üçte biri kahvaltı öğününü atladıklarını bildirmiştir. BD öğrencilerinde bu oran (\%15.2) diğer iki bölüm öğrencilerinden anlamlı olarak düşüktür (Tablo 1). Kahvaltı öğününü atlamak bireylerin diyet kalitelerini olumsuz etkileyebilir. Ülkemizde üniversite öğrencilerinde yürütülen iki farklı çalışmada yaklaşık dört öğrenciden üçünün geliştirilmesi gereken diyet kalitesine sahip olduğu saptanmıştır $(23,24)$. Bu çalışmada, tüm öğrencilerin \%64.0’nün geliştirilmesi gereken, \%35.3’nün yetersiz diyet kalitesinin olduğu; BD öğrencilerinin diyet kalitelerinin TF ve SB öğrencilerine göre daha iyi olduğu bulunmuştur. Ayrıca BD öğrencilerinin SYİ2015 puan ortalamaları en yüksek ve TF öğrencilerinin ise en düşük olduğu saptanmıştır (Tablo 2). Bu durum sağlık okuryazarlığında olduğu gibi beslenme ve spor eğitiminin etkisini ortaya koymaktadır.

Sonuç olarak bireylerin sağlık okuryazarlığının yeterli düzeyde olması diyet kalitelerini olumlu yönde etkilemiştir. Ancak yeterli düzeyde diyet kalitesine sahip yalnızca 4 öğrenci olmasının nedenleri araştırılmalıdır. Her ne kadar bu araştırmada örneklem büyüklüğü $(n=580)$ yeterli görünse de ve bulgular literatürle uyumlu olsa da araştırma evrenine ulaşım oranının düşük olması ( \%30) ve tabakalama örneklemeyönteminin uygulanamamasıaraştırmanın sinırlılıklarındandır. Sağlık okuryazarlığı düzeyinin belirlenmesi için toplum genelini kapsayan çalışmalar yapılması önerilir. Önümüzdeki yıllarda yapılacak olan Türkiye Beslenme ve Sağlık Araştırmalarında sağlık okuryazarlığı ve diyet kalitesi belirlenerek aralarındaki ilişkinin saptanması bu önerinin gerçekleşmesini sağlayabilir.

Yazarlık katkısı - Author contributions: Çalışmanın tasarımı: MY, YYF, FHG, TAK; Çalışma verilerinin elde edilmesi: YYF, FHG, TAK; Verilerin analiz edilmesi: $M Y$, YYF, FHG; Makale taslağının oluşturulması: MY, YYF, FHG; İçerik için eleştirel gözden geçirme: MY, YYF, FHG, TAK; Yayinlanacak versiyonun son onayl: MY, YYF, FHG, TAK. - Study design: MY, YYF, FHG, TAK; Data collection: YYF, FHG, TAK; Data analysis: MY, YYF, FHG; Draft preparation: $M Y$, YYF, FHG; Critical review for content: MY, YYF, FHG, TAK; Final approval of the version to be published: $M Y, Y Y F, F H G$, TAK.

Etik Kurul Onayı - Ethics approval: Araştırmanın yürütülebilmesi için Erciyes Üniversitesi Sosyal ve Beşeri Bilimler Etik Kuruldan onay alınmıştır (Karar no:118 Karar Tarihi:26.11 2019). - The ethics committee of Erciyes University's Social Sciences and Humanities gave its approval to conduct the study. 
Çıkar çatışması - Conflict of interest: Yazarlar çıkar çatışması olmadığını beyan ederler. - The authors declare that they have no conflict of interest.

\section{KAYNAKLAR}

1. Türkiye Beslenme Rehberi TÜBER 2015, T.C. Sağllk Bakanlığı Yayın No: 1031, Ankara 2019.

2. Kourlaba G, Panagiotakos DB. Dietary quality indices and human health: A review. Maturitas. 2009;62(1):1-8.

3. Krebs-Smith SM, Pannucci TE, Subar AF, Kirkpatrick SI, Lerman JL, Tooze JA, et al. Update of the Healthy Eating Index: HEI-2015. J Acad Nutr Diet. 2018;118(9):1591-11.

4. Eichler K, Wieser S, Brügger U. The costs of limited health literacy: A systematic review. Int. J Public Health. 2009;54(5):313-9.

5. Weiss BD, Mays MZ, Martz W, Castro KM, DeWalt DA, Pignone MP, et al. Quick assessment of literacy in primary care: The Newest Vital Sign. Ann Fam Med. 2005;3(6):514-8.

6. Speirs KE, Messina LA, Munger AL, Grutzmacher SK. Health literacy and nutrition behaviors among low-income adults. J Health Care Poor Underserved. 2012;23(3):1082-9.

7. Von Wagner C, Knight K, Steptoe A, Wardle J. Functional health literacy and health-promoting behaviour in a national sample of British adults. J Epidemiol Community Heal. 2007;61(12):1086-4.

8. Zoellner, J, You W, Connell C, Smith-Ray RL, Allen K, Tucker KL, et al. Health literacy is associated with healthy eating index scores and sugar-sweetened beverage intake: Findings from the rural Lower Mississippi Delta. J Am Diet Assoc. 2011;111(7):1012-8.

9. Özdemir H, Alper Z, Uncu Y, Bilgel N. Health literacy among adults: A study from Turkey. Health Educ. Res. 2010;25(3):464-13.

10. Rakıcıoğlu N, Acar Tek N, Ayaz A, Pekcan G. Yemek ve besin fotoğraf kataloğu. Ankara: Hatiboğlu Yayınevi; 2012.

11. Beslenme Bilgi Sistemi-BeBiS, Versiyon 7.2; 2011, İstanbul.

12. Pekcan G. Beslenme Durumunun Saptanması. Baysal A. ve ark. Editörler. Diyet El Kitabı. Ankara: Hatiboğlu Yayınları;2013.s.67-142.
13. Ollberding NJ, Wolf RL, Contento I. Food label use and its relation to dietary intake among US adults. J Am Diet Assoc. 2011;111(5):47-4.

14. Rothman RL, Housam R, Weiss H, Davis D, Gregory R, Gebretsadik T, et al. Patient understanding of food labels: The role of literacy and numeracy. Am J Prev Med. 2006; 31(5):391-8.

15. Noblin A, Gabriel MH, Cortelyou-Ward K, Holmes K. Health literacy among visiting college students in the US: A pilot study. J Am Coll Health. 2020:1-9.

16. Olyani S, Tehrani H, Esmaily H, Rezaii MM, VahedianShahroodi M. Assessment of health literacy with the Newest Vital Sign and its correlation with body mass index in female adolescent students. Int J Pediatr Adolesc Med. 2020;32(2):20170103.

17. Anastasiou K, Miller M, Dickinson K. The relationship between food label use and dietary intake in adults: A systematic review. Appetite. 2019;138:280-11.

18. Cha E, Kim KH, Lerner HM, Dawkins CR, Bello MK, Umpierrez G, et al. Health literacy, self-efficacy, food label use, and diet in young adults. Am J Health Behav. 2014;38(3):331-9.

19. Sharif I, Blank AE. Relationship between child health literacy and body mass index in overweight children. Patient Educ Couns. 2010;79(1):43-5.

20. Vernon JA, Trujillo A, Rosenbaum, S, DeBuono B. Low health literacy: Implications for national health policy. Washington DC: Department of Health Policy, School of Public Health and Heatlh Services, The George Washington University, 2007.

21. Yıldırım İ, Yıldırım Y, Tortop Y, Poyraz A. Afyon Kocatepe Üniversitesi Beden Eğitimi ve Spor Yüksekokulu öğrencilerinin beslenme alışkanlıkları ve bunları etkileyen faktörler. Uluslararası İnsan Bilimleri Dergisi. 2011;8(1):1375-16.

22. Vançelik S, Önal SG, Güraksın A, Beyhun E. Üniversite öğrencilerinin beslenme bilgi ve alışkanlıkları ile ilişkili faktörler. TSK Koruyucu Hekimlik Bülteni. 2007;6(4):242-8.

23. Erçim RE, Pekcan G. Genç yetişkinlerin beslenme durumunun Sağlıklı Yeme İndeksi-2005 ile değerlendirilmesi. Bes Diy Derg. 2014;42(2):91-8.

24. Yıldız A. Üniversite öğrencilerinin sağlıklı yeme indekslerinin belirlenmesi [Yüksek Lisans Tezi]. Okan Üniversitesi Sağlık Bilimleri Enstitüsü, İstanbul; 2016. 